\section{Tema "Keluarga" dan Relevansinya dalam Pembelajaran Bahasa Jerman}

\author{
Sri Santia S. ${ }^{1}$, Muh. Anwar ${ }^{2}$ \\ Universitas Negeri Makassar
}

Email: santiathya@gmail.com

\begin{abstract}
Abstrak. Penelitian ini bertujuan untuk memperoleh data tentang tema "keluarga" dan relevansinya dalam pembelajaran bahasa Jerman siswa kelas XII IIS SMA Negeri 11 Makassar. Penelitian ini merupakan penelitian deskriptif kualitatif. Populasi penelitian ini adalah seluruh siswa kelas XII SMA Negeri 11 Makassar yang belajar bahasa Jerman yang terdiri dari 3 (tiga) kelas yaitu kelas XII IIS 1, XII IIS 2 dan XII IIS 3 dengan jumlah 106 orang. Teknik sampel yang digunakan adalah purposive sampling yang berjumlah 36 siswa. Teknik pengumpulan data digunakan angket terbuka. Data yang telah diperoleh dianalisis secara deskriptif kualitatif. Hasil penelitian menunjukkan bahwa kehidupan keluarga di Jerman sangat baik. Hal ini dapat dilihat berdasarkan budaya hidup melalui sikap kemandirian, kesetaraan hak (pekerjaan) dalam keluarga, dan waktu luang. Relevansi dalam pembelajaran pada penelitian ini terutama pada tema budaya bahwa tema-tema seperti ini adalah tema yang cocok untuk dipelajari karna tujuan pembelajaran bahasa tidak hanya sampai kepada penguasaan bahasa tetapi juga budayanya yaitu dengan mencari materimateri pembelajaran yang sifatnya berkaitan dengan tema budaya dan universal tapi disatu sisi bersifat spesifik tujuannya agar proses pembelajaran itu jauh lebih cepat terjadi karena tema yang dipakai atau dipelajari juga ada dalam budaya kita. Selain itu kita melihat keluarga jerman sangat tepat waktu dan disiplin, jadi relevansinya dalam proses pembelajaran sangat dijunjung tinggi sifat kedisiplinan dan ketepatan waktu.
\end{abstract}

Kata Kunci: Thema: "Familie", Relevanz

\section{INTERFERENCE Journal of Language, Literature,and Linguistics}

\author{
E-ISSN: 2721-1835 \\ P-ISSN: 2721-1827
}
Submitted
: May $3^{\text {rd }}, 2021$
Accepted
: May $21^{\text {th }}, 2021$

Abstract. This study aims to obtain data on the theme of "family" and its relevance in learning German for class XII IIS SMA Negeri 11 Makassar. This research is a qualitative descriptive study. The population of this study were all students of class XII SMA Negeri 11 Makassar who studied German which consisted of 3 (three) classes, namely class XII IIS 1 , XII IIS 2 and XII IIS 3 with a total of 106 people. The sample technique used was purposive sampling, amounting to 36 students. The data collection technique used an open questionnaire. The data that has been obtained were analyzed descriptively qualitatively. The results showed that family life in Germany was very good. This can be seen based on the culture of life through the attitude of independence, equal rights (work) in the family, and free time. The relevance of learning in this study is mainly on cultural themes that themes like this are suitable themes to be studied because the purpose of language learning is not only to mastery of language but also to culture, namely by looking for learning materials that are related to cultural and universal themes. but on the one hand it is specific in purpose so that the learning process occurs much faster because the themes used or studied also exist in our culture. In addition, we see that the German family is very punctual and disciplined, so its relevance in the learning process is highly respected by the nature of discipline and timeliness. 


\section{PENDAHULUAN}

Bahasa adalah alat komunikasi yang sangat penting bagi manusia. Melalui bahasa manusia dapat berkomunikasi antar sesama manusia. Dewasa ini manusia tidak hanya dituntut untuk bisa menguasai bahasa nasional, akan tetapi juga dituntut bisa menguasai bahasa asing.

Di Indonesia bahasa asing sudah diajarkan di sekolah pada jenjang Sekolah dasar sampai jenjang sekolah menengah atas (SMA, SMK maupun MA) hal tersebut senada dengan yang dikemukakan oleh Tahir, R. A., Rijal, S., \& Fatimah, S. (2020); Alvionicha, F., Jufri, J., \& Dalle, A. (2021); Nur, M., Burhanuddin, B., \& Mannahali, M. (2021). Bahasa Inggris yang dianggap sebagai bahasa asing bahkan menjadi pelajaran wajib di sekolah-sekolah. Selain bahasa Inggris, bahasa Jerman juga mendapatkan tempat sebagai bahasa asing yang diajarkan di Indonesia.

Berdasarkan Kurikulum bahasa Jerman tahun 2013 menyebutkan bahwa tujuan pembelajaran bahasa Jerman adalah agar peserta didik dapat menguasai dengan baik bahasa Jerman melalui empat kompetensi berbahasa di antaranya: menyimak (Hören), berbicara (Sprechen), membaca (Lesen) dan menulis (Schreiben). Selain itu, terdapat juga dua unsur kebahasaan yaitu tata bahasa (Strukturen) dan kosakata (Wortschatz).

Selain itu, dalam pembelajaran bahasa Jerman juga tidak pernah terlepas dari unsur kebudayaan. Unsur kebudayaan yang dimaksudkan adalah bagian dari pengetahuan Kontrastif Interkulturelle, seperti yang terkait dengan keadaan geografis, perkembangan sejarah, sosial ekonomi, kekuatan politik, adat istiadat, cara berpikir, dan aspek kehidupan yang lain bagi masyarakat penutur asli bahasa yang dipelajari. Integrasi pengetahuan Interkulturelle dalam pengajaran bahasa Jerman memegang peranan penting, karena tanpa memperoleh pengetahuan ini siswa tidak akan memahami budaya Jerman yang sebenarnya.

Terdapat beberapa hasil penelitian terkait dan relevan tentang Interkulturelle seperti yang dilakukan oleh Saleh (2017) dengan judul Keterampilan pemahaman antar budaya dalam pembelajaran membaca melalui Flipped Learning Model (FLM) menunjukkan bahwa FLM memiliki pengaruh yang signifikan terhadap minat belajar membaca siswa. Hal ini didukung oleh persentase kemampuan pemahaman lintas budaya sebesar $80,20 \%$. Selanjutnya penelitian yang dilakukan oleh Megawardhani, N. (2017) menunjukkan bahwa pengenalan Landeskunde terintegrasi dengan pembelajaran berbahasa. Penelitian terkait interkulturelle kommunikation juga telah dilakukan oleh Nurfadilla, N., Rijal, S., \& Usman, M. (2020); Setiawan, A. K. (2011); Saleh, N., Rijal, S., \& Mannahali, M. (2020); Kudriyah, S. (2018) bahwa tema-tema karya sastra Bahasa Jerman yang relevan untuk di ajarkan pada siswa yaitu tema keluarga, kehidupan sehari-hari, ketuhanan, alam, dan kesehatan dengan memperhatikan level Bahasa siswa.

Berkaitan dengan hal tersebut, tema keluarga merupakan salah satu teman yang relevan untuk diajarkan pada siswa di sekolah. Keluarga adalah unit terkecil dari masyarakat yang terdiri atas kepala keluarga dan beberapa orang yang terkumpul dan tinggal di suatu tempat di bawah satu atap dalam keadaan saling ketergantungan. Mubarak (2009) menjelaskan bahwa Keluarga merupakan perkumpulan dua atau lebih individu yang terikat oleh hubungan perkawinan, 
hubungan darah ataupun adopsi, dan setiap anggota keluarga saling berinteraksi antara satu dengan lainnya.

\section{METODE PENELITIAN}

Pendekatan dalam penelitian ini menggunakan pendekatan kualitatif yakni suatu penelitian yang lebih menekankan pada pengumpulan data yang bersifat kualitatif (tidak berbentuk angka) dan menggunakan analisis kualitatif dalam pemaparan data, analisis data dan pengambilan kesimpulan. Jenis penelitian yang digunakan adalah penelitian kualitatif yaitu penelitian yang menghasilkan data deskriptif berupa kata-kata tertulis atau lisan dari orang-orang dan perilaku yang dapat diamati.

Populasi dalam penelitian ini adalah seluruh Siswa kelas XII IIS SMAN 11 Makassar yang belajar bahasa Jerman yang terdiri dari tiga kelas yaitu kelas XII IIS 1, XII IIS 2 DAN XII IIS 3 dengan jumlah 106 orang. Sampel yang digunakan dalam penelitian ini menggunakan purposive sampling, yaitu teknik yang menentukan sampel secara non random berdasarkan kriteria-kriteria tertentu yang sesuai dengan tujuan penelitian. Jumlah siswa yang diperlukan yaitu sejumlah 36 siswa yang berasal dari kelas XII IIS 2.

Dalam penelitian ini peneliti memberikan pertanyaan kepada siswa berupa angket terbuka yaitu angket yang memberikan kebebasan bagi responden untuk memberikan jawaban atau tanggapan Pertanyaan dalam penelitian ini diberikan kepada Siswa SMA yang belajar bahasa Jerman khususnya siswa-siswi kelas XII IIS 2 SMA Negeri 11 Makassar yang berjumlah 36 orang.

Data yang telah diperoleh akan dianalisis secara kualitatif serta diuraikan dalam bentuk deskriptif. Teknik analisis data yang digunakan dalam penelitian ini adalah menggunakan langkah-langkah yaitu: pengumpulan data (data collection), display data, verifikasi dan penegasan kesimpulan (concultion drawing and verification).

\section{HASIL DAN PEMBAHASAN}

Dalam hal ini diuraikan secara mendetail tentang hasil penelitian dan pembahasan, yaitu mengenai gambaran kehidupan keluarga di Jerman serta bagaimana tanggapan siswa terhadap keluarga Jerman terutama tentang sikap kemandirian yang diterapkan (Selbständigkeit), persamaan hak (Arbeiten) dalam keluarga serta aktifitas waktu luang (Freizeit).

Data hasil penelitian diperoleh dari beberapa pertanyaan yang diberikan kepada siswa berupa pertanyaan terbuka serta memperlihatkan video-video singkat dalam buku Netzwerk A1 yang masing-masing videonya berlangsung selama kurang lebih 3 menit mengenai kehidupan keluarga Jerman .

Dalam pembelajaran bahasa Jerman siswa tidak hanya dituntut untuk mengetahui seputar struktur grammatik, kosakata dan aspek kompetensi berbahasanya saja namun siswa juga diberi pemahaman untuk mengenal bagaimana budaya dari bahasa yang dipelajari agar tidak terjadi kesalahpahaman. Dengan demikian siswa bisa mengetahui bagaimana budaya asing (Fremdekultur) khususnya budaya Jerman tentang bagaimana kehidupan keluarganya, kemandirian yang diterapkan dari orang tua pada anaknya, persamaan hak (pekerjaan) dalam 
keluarga Jerman serta waktu luang yang dilakukan oleh keluarga Jerman. Berikut ini Jawaban responden dan pernyataan yang mendukung penelitian ini :

\section{Kehidupan Keluarga Di Jerman}

Berikut hasil jawaban dari responden (R7) tentang kehidupan keluarga di Jerman disajikan dalam bentuk kutipan yaitu:

"Menurut saya kehidupan keluarga di Jerman dan di Indonesia itu sangat berbeda, dapat dilihat dari kehidupan sehari-hari. Keluarga di Jerman tidak lagi berprinsip banyak anak banyak rezeki. Keluarga di Jerman adalah keluarga mandiri. Setelah seorang anak berusia 17 tahun, mereka segan meminta bantuan kepada orang tuanya. Mereka mulai mencari kehidupan sendiri. Semua anggota keluarganya punya kebebasan berpendapat.

Pendapat tersebut sesuai dengan pernyataan yang diungkapkan oleh Alisa (Praktikantin aus Deutschland) bahwa:

"Ich glaube das erste Mal in hier grossten Städten vor allem die Familie mittlerweile eher klein sind. Also Mutter und Vater und wenige Kinder hier gab es grosse Familie jetzt und das oft sind kleine Familien und ich glaube dass viele Eltern sehr gut um ihre Kinder kümmern. Die Kinder haben auch viele Freiheiten, die können ihren Hobbys nachgehen, die können wenn sie 16 oder 18 Jahren sind auch abends länger wegbleiben haben, also viele Möglichkeiten und ihre eigenen Wünsche umzusetzen und Träume zu verfolgen und die Eltern unterstützen zu grossen Teilen ihre Kinder dabei und ich glaube es ist sehr gut. Sonst gibt es auch viele Familie Aktifitäten, die man gerne zusammen macht zum beispiel Sonntag machen Familie gerne zusammen Ausflüge, es wird auch zusammen gefrühstuck, oder zusammen zu Abend gegessen, damit man sich auch in der Familie sieht"

Maksud dari pernyataan diatas adalah "saya pikir, pertama kali di kota-kota besar, terutama pada keluarga sekarang agak kecil, hanya ada ibu , ayah dan beberapa anak, tetapi sekarang mereka adalah keluarga kecil dan saya percaya bahwa orang tua sangat peduli merawat anak- anak mereka dengan sangat baik. Anak-anak juga punya banyak kebebasan untuk mengejar hobbi yang dapat mereka lakukan pada malam hari. Ketika mereka berusia 16 atau 18 tahun, mereka sudah bisa pergi atau berada diluar rumah lebih lama, jadi mereka memiliki banyak peluang untuk mengimplementasikan keinginan mereka sendiri dan mengejar impiannya. Sebagaian besar orang tua mendukung anak-anak mereka. Saya pikir itu sangat baik, jika tidak banyak kegiatan keluarga yang suka mereka lakukan bersama-sama. Misalnya pada hari minggu mereka bertamasya bersama, sarapan atau makan malam bersama. Hal itu yang biasa ditemukan dalam sebuah keluarga.

Berdasarkan hasil kutipan dari jawaban responden diatas dapat dikatakan bahwa kehidupan keluarga di Jerman mengajarkan banyak hal positif yang patut untuk dicontoh. Hal ini dapat dilihat pada segi kualitas dan kuantitas. Berdasarkan kualitas bahwa keluarga Jerman adalah keluarga mandiri. Sedangkan dari segi kuantitas bahwa keluarga Jerman tidak lagi berprinsip banyak anak banyak rezeki, karena mayoritas orang Jerman lebih memprioritaskan pekerjaan. 


\section{Sikap Kemandirian Yang Diterapkan Keluarga Dijerman}

Berikut ini adalah jawaban responden (R11) mengenai sikap kemandirian yang diterapkan keluarga di Jerman:

"Kemandirian sikap yang ditanamkan sedari kecil terlihat dari seorang anak dalam video tersebut yang melayani tamunya. Kemandirian yang perlu terus diterapkan agar tidak terjadinya ketergantungan terhadap orang tua, dan dapat hidup tanpa terlalu membebani orang tua".

Temuan tersebut juga diungkapkan oleh Laura (Praktikantin aus Deutschland) bahwa:

"Also ich würde sagen, dass wenn man ungefähr 16 ist, ab 16 darf man in Deutschland Skyline Club gehen oder auf eine Party gehen wir raus gehen abends und tanzen und $a b 16$ würde ich sagen sind die Kinder selbständiger und Jugendlichen, also sie gehen ohne die Eltern raus abends auch und schlafen bei Freunden und übernachten dort und ja wahrscheinlich so geht in der man ist 19 oder 20, dann ziehen die Kinder eben moistens aus und werden dann ganz selbständig viele sind aber immer noch abhängig von ihren Eltern. Als viele stehen immer noch in Kontakt mit den Eltern und die Eltern helfen dann trotzdem den Kindern auch, wenn sie ausgezogen sind, also wenn man ein problem hat, z.b Wenn ich ein Problem habe, rufe ich meine Mama an und erzähle ihr das und dann hilft sie mir trotzdem auch, wenn ich nicht mehr zu Hause wohne".

Maksud dari pernyataan diatas, bahwa ketika anak berusia sekitar 16 tahun mereka sudah bisa pergi ke Skyline Club di Jerman atau ke pesta, keluar di malam hari dan menari. Anak-anak juga lebih mandiri dan bisa pergi keluar rumah tanpa orang tua dan menginap di rumah teman-temannya. Ketika anak berusia 19 atau 20 tahun, biasanya mereka sudah bisa tinggal sendiri dan mandiri sepenuhnya. Akan tetapi masih banyak anak yang bergantung pada orang tuanya karena orang tua masih membantu anak-anak saat ada masalah.

Berdasarkan hasil kutipan dari jawaban responden diatas dapat dikatakan bahwa sikap kemandirian yang diterapkan di keluarga Jerman sangat bermanfaat dan membentuk moral anak sejak dini karena Jerman dikenal sebagai salah satu negara dengan pola asuh terbaik, terutama dalam hal kemandirian. di Jerman, prinsip utama membesarkan anak adalah dengan menanamkan selbstaendigkeit yang berarti kemandirian atau otonomi. Mereka memiliki pola dan budaya tersendiri dalam mendidik anak. Orang tua di Jerman mulai menanamkan kemandirian terhadap anaknya dari usia dini. Anak-anak sudah dilatih untuk bisa melakukan berbagai hal mulai dari hal-hal kecil tanpa bantuan orang tua. Hal ini sesuai dengan video dalam buku Netzwerk (A1) yang ditayangkan dimana dalam video tersebut terlihat seorang anak yang sedang melayani tamu dan melakukan pekerjaan rumah tanpa permintaan orang tua.

\section{Kesetaraan Hak (Pekerjaan) dalam Kehidupan Keluarga Di Jerman}

Berikut ini adalah jawaban responden (R2) mengenai persamaan hak (pekerjaan) kehidupan keluarga di Jerman:

"Tidak ada persamaan hak dalam kehidupan keluarga di Jerman. Mereka hanya memikirkan bagaimana kebutuhan bisa terpenuhi" 
Pendapat tersebut diperkuat oleh Laura (Praktikantin aus Deutschland)
bahwa: "In Deutschland ist es so, dass schon relative gleichberechtigtes Frauen dürfen machen was sie wollen. Sie können machen, was sie wollen. Sie müssen jemanden fragen. Ich kann studieren, was ich möchte und ich muss auch nicht mein Vater z.b Fragen. Also ich kann machen was ich möchte als Frau und ich würde sagen zwischen Mutter und Vater ist auch so, dass das eine Gleichberechtigung, aber ich weiss das auch noch viele Familien gibt in denen das nicht so ist in denen der Mann arbeitet z.b und die Frau ist immer zu Hause bei den Kindern, dass es manchmal ist das doch so, es gibt aber auch viele Familien in denen das Umgekehrt ist in den der Vater dann zu Hause ist und die Mutter geht arbeiten. Das ist meistens entscheiden die Familie das selber, also ich würde schon sagen, dass die Gleichberechtigung schon sehr grob ist in Deutschland. Das beide als vor dem Gesetz z.b haben auch beide die gleichen Rechte, also Männer und Frauen vor dem Gesetz kein Unterschied gemacht. Es gibt keine anderen Regeln für Frauen und Männer haben die gleichen Regeln in Deutschland".

Maksud dari kutipan di atas: Di Jerman, perempuan dengan hak yang relatif sama diperbolehkan melakukan apa yang mereka inginkan. Mereka dapat melakukan apa yang mereka inginkan. Contohnya, saya bisa belajar apapun yang saya mau dan saya tidak perlu bertanya pada ayah saya. Jadi saya dapat melakukan apa yang saya inginkan sebagai seorang wanita dan saya akan mengatakan bahwa ada kesetaraan antara ibu dan ayah, tetapi saya tahu bahwa ada juga banyak keluarga di mana hal ini tidak terjadi, di mana pria bekerja dan perempuan selalu berada di rumah bersama anak-anak.

Tetapi banyak juga keluarga yang sebaliknya terjadi di mana ayah di rumah dan ibu pergi bekerja. Sebagian besar keluarga yang memutuskan sendiri, saya berpendapat bahwa kesetaraan sudah sangat tinggi di Jerman. Keduanya memiliki hak yang sama di depan hukum. Jadi laki-laki dan perempuan memiliki aturan yang sama dan tidak ada perbedaan dihadapan hukum.

Berdasarkan beberapa pendapat di atas dapat disimpulkan bahwa kesetaraan persamaan hak (pekerjaan) keluarga antara laki-laki dan perempuan sudah sangat adil di Jerman. Di Jerman, tidak selamanya istri yang harus mengurus rumah tangga dan suami yang bekerja, begitupun sebaliknya. Seperti dalam video buku Netzwerk (A1) yang ditayangkan dan yang dikutip dari buku Studio D B1 bahwa suami tidak dituntut untuk harus bekerja, dia juga bisa membantu mengurus pekerjaan rumah tangga dan mengasuh anak begitupun juga dengan peran seorang istri. Hal ini sesuai dengan situasi hukum yaitu kesetaraan antara laki-laki dan perempuan dijamin melalui pasal 3 dalam Undang-Undang Dasar Republik Federal Jerman yang menyatakan:

"Semua orang harus sama dihadapan hukum. Laki-laki dan perempuan harus memiliki hak yang sama".

\section{Waktu Luang Keluarga Di Jerman}

Berikut ini adalah jawaban responden (R14) mengenai waktu luang keluarga di Jerman. 
“Di Jerman pada saat waktu luang biasanya menyempatkan waktu bersama keluarga jadi, walaupun masing-masing sibuk, kedekatan dan hubungan antara orang tua dan anak tetap terjalin dengan baik".

Pendapat tersebut juga diungkapkan oleh Alisa (Praktikantin aus Deutschland) bahwa:

"Also ich würde sagen viele Kinder und auch Erwachsene machen gerne Sport sehr viel Sport. Es gibt in Deutschland viele Sportvereine Kiel FuBball. Fubball ist ganz wichtig oder reiten, Tenis spielen, das wird sie auch viel gemacht, aber ich werde alles mit viel Sport gemacht, aber man geht auch gerne ins Kino oder ins Theater und ins Museum. also so Kulturelle Aktivitäten, die wären auch gerne gemacht und dann sonst den Teppich gerade Jugendliche sehr oft mit ihren Freundinnen und Freunden um essen zu gehen oder etwas trinken zu gehen und abends am wochenende gehen auch viele gerne mal Tanzen feiern und etwas trinken".

Maksud dari kutipan di atas, di Jerman banyak anak-anak dan orang dewasa suka berolahraga. Ada banyak klub olahraga sepak bola Kiel di Jerman. Sepak bola itu sangat penting atau berkuda, bermain tenis, juga banyak dilakukan. Selain itu mereka juga suka pergi ke bioskop, teater dan museum. Jadi kegiatan budaya yang akan menyenangkan untuk dilakukan terutama anak remaja. Mereka sangat sering keluar untuk makan atau minum dengan teman-teman mereka di malam hari di akhir pekan.

Berdasarkan beberapa uraian di atas menunjukkan bahwa orang Jerman secara umum dianggap rajin dan efisien. Mereka punya banyak waktu luang, sekitar hampir empat jam sehari. Menurut hasil studi "Stiftung für Zukunftsfragen", mereka memanfaatkan waktu luang dengan menonton televisi, melakukan hobi yang disukai seperti olahraga, ski, menari, ke bioskop dan lain-lain. Seperti dalam video buku Netzwerk (A1) yang ditayangkan, meskipun orang tua sibuk dengan pekerjaan tetapi mereka tetap meluangkan waktu untuk berkumpul bersama keluarga. Mereka masih menyempatkan untuk membantu anaknya mengerjakan tugas rumah dan makan bersama. Karena waktu luang sangat penting bagi keluarga di Jerman. Berkumpul bersama keluarga adalah momen penting untuk mempererat hubungan satu sama lain.

\section{Kegiatan yang Dilakukan Keluarga Jerman pada saat Waktu Luang}

Berikut ini adalah jawaban responden (R13) mengenai kegiatan waktu luang yang dilakukan keluarga di Jerman.

"Masyarakat Jerman lebih menggunakan waktu luangnya kepada hal-hal yang positif yang bisa berguna bagi tubuh seperti berolahraga, bersepeda dan juga menggunakan waktu luang untuk menambah wawasan seperti membaca, menulis dan lain-lain".

Pendapat tersebut juga di dukung oleh Opaschowschki (Funk, Kuhn, Demme:2015):

"Seit den 7oer Jahren gehören Fernsehen, Radio hören und Zeitung lesen zu den beliebtesten Freizeitaktivitäten. Der Alltag ist stressing, die Leute freuen sich auf das Wochenende und wollen sich ausruhen, nichts tun und ausschlafen. Immer mehr Deutsche fahren Fahrrad oder skaten. Andere treffen sich mit Freunden und kochen zusammen. Viele beschäftigen sich mit einem Haustier. Teure Freizeitaktivitäten wie 
z.B. ins Kino gehen, sich zum Essen verabreden oder in die Disko gehen sind out. Die Bundesbürger machen eine neue Efahrung: Freizeit muss nicht immer Geld kosten".

Artinya: Sejak 70 tahun yang lalu aktifitas waktu luang seperti menonton televisi, mendengar radio dan membaca majalah menjadi aktifitas waktu luang yang paling disukai. Ketika stress, orang-orang lebih senang bersantai tetapi tidak tidur. Orang di Jerman lebih sering bersepeda atau skaten. bertemu dengan teman-teman dan memasak bersama. Banyak juga kesibukan dengan hewan peliharaan. Aktifitas waktu luang yang berharga seperti ke bioskop, makan malam bersama atau ke Diskotik. Orang Jerman menganggap itu adalah suatu pengalaman yang baru: Waktu luang tidak selalu bisa dibayar dengan uang.

Berdasarkan ungkapan dari beberapa responden seperti yang tercantum dalam kutipan di atas dan dikutip dari Deutsche Welle serta video dalam buku Netzwerk (A1) yang ditayangkan maka dapat disimpulkan bahwa kegiatan santai yang paling nyaman untuk menghabiskan waktu senggang mereka adalah menonton televisi. Ini salah satu hobi yang populer di Jerman. Seperempat warga Jerman juga melakukan olahraga ski atau snowboard pada musim dingin di pegunungan Alpen atau di dataran tinggi dan melakukan skating atau arena luncur pada musim dingin.

Berdasarkan pernyataan dari beberapa poin di atas dapat disimpulkan bahwa kehidupan keluarga di Jerman mempunyai banyak nilai positif dan bagus untuk dijadikan contoh. Hal ini dapat dilihat melalui kebiasaan (budaya) hidup dari segi penanaman sikap kemandirian anak sejak dini, kesetaraan hak (pekerjaan) antara laki-laki dan perempuan bersama keluarga.

Relevansi dalam pembelajaran pada penelitian ini yang berkaitan dengan tema budaya bahwa tema-tema seperti ini adalah tema yang cocok untuk dipelajari karena tujuan pembelajaran bahasa tidak hanya sampai kepada penguasaan bahasa tetapi juga budayanya yaitu dengan mencari materi-materi pembelajaran yang sifatnya Kultur tema dan universal tapi satu sisi spesifik tujuannya agar proses pembelajaran itu jauh lebih cepat terjadi karena tema yang dipakai atau dipelajari juga ada dalam budaya kita. Oleh karena itu, salah satu contoh tema budaya yaitu tema keluarga sangat relevan untuk diajarkan karena orang Indonesia sudah punya latar belakang pemikiran tentang tema tersebut dan pada saat tema itu muncul pada versi lain maka jauh lebih cepat dipahami .Selain itu kita melihat keluarga Jerman sangat tepat waktu, disiplin dan mandiri, jadi relevansinya dalam proses pembelajaran sangat menjunjung tinggi sifat kedisiplinan, ketepatan waktu dan kemandirian yang bisa diterapkan dalam kelas maupun kehidupan sehari-hari.

\section{KESIMPULAN}

Berdasarkan hasil analisis data yang telah diuraikan pada bab IV di atas, maka dapat disimpulkan bahwa kehidupan keluarga di Jerman mengajarkan banyak hal positif dari segi kualitas dan kuantitas yang patut untuk dicontoh. Hal ini dapat dilihat berdasarkan budaya hidup melalui sikap kemandirian, kesetaraan hak (pekerjaan) dalam keluarga, dan waktu luang.

Pengetahuan Imterkulturelle dalam pembelajaran bahasa Jerman akan membantu siswa memahami dengan benar budaya-budaya Jerman dan Relevansi dalam pembelajaran pada penelitian ini yang berkaitan dengan tema budaya bahwa 
tema-tema seperti ini adalah tema yang cocok untuk dipelajari karna tujuan pembelajaran bahasa tidak hanya sampai kepada penguasaan bahasa tetapi juga budayanya yaitu dengan mencari materi-materi pembelajaran yang sifatnya Kultur tema dan universal tapi satu sisi spesifik tujuannya agar proses pembelajaran itu jauh lebih cepat terjadi karna tema yang dipakai atau dipelajari juga ada dalam budaya kita.

\section{DAFTAR PUSTAKA}

Alvionicha, F., Jufri, J., \& Dalle, A. (2021). Keterampilan Menulis dan Berbicara Bahasa Jerman Siswa Berbasis Model Pembelajaran SAUD. Interference: Journal of Language, Literature, and Linguistics, 2(1), 1-10.

Deutsche Welle. (2014). Diakses dari https://www.dw.com/id/memanfaatkan-waktuluang-di-jerman/g-17772642 pada tanggal 14 Oktober 2020 pukul 23:00 WITA. 2019. Familie in Deutschland. Diakses dari https://learn-ger-man.dw.com/de/fam-ilieindeutschland/l-40558163/rs-39363585Pada tanggal 1 September 2019 Pukul 23:06 WITA

Kudriyah, S. (2018). INTERKULTURELLE LANDESKUNDE ZUR UNTERSTÜTZUNG DER KOMMUNIKATIONSKOMPETENZ.

Megawardhani, N. (2017). ANALISIS MATERI LANDESKUNDE YANG TERINTEGRASI DALAM PEMBELAJARAN KETERAMPILAN BAHASA JERMAN (Doctoral dissertation, Universitas Pendidikan Indonesia).

Mubarak, W, I \& Chayatin, N (2009). Ilmu Keperawatan Komunitas Pengantar dan Teori. Jakarta : Salemba Medika.

Nur, M., Burhanuddin, B., \& Mannahali, M. (2021). Hubungan Antara Penguasaan Kosakata dengan Keterampilan Menulis Puisi Bahasa Jerman. Interference: Journal of Language, Literature, and Linguistics, 2(1), 64-70.

Nurfadilla, N., Rijal, S., \& Usman, M. (2020). PENGAJARAN SASTRA BAHASA JERMAN DI SEKOLAH MENENGAH ATAS (SMA). Interference: Journal of Language, Literature, and Linguistics, 1(2), 121-127.

Saleh, N., Rijal, S., \& Mannahali, M. (2020, November). Model Pembelajaran NURS dalam Keterampilan Menulis Bahasa Jerman. In Seminar Nasional Pengabdian Kepada Masyarakat.

Saleh, Nurming. (2017).Pengembangan Bahan Ajar Membaca Memahami (Leseverstehen) Berbasis Interkulturelle Bagi Mahasiswa Program Studi Pendidikan Bahasa Jerman Jurusan Pendidikan Bahasa Asing FBS UNM. Disertasi. Makassar: FBS UNM

Setiawan, A. K. (2011). Integrasi pendidikan karakter dalam pembelajaran berbasis interkultural. Jurnal Pendidikan Karakter, 1(1).

Tahir, R. A., Rijal, S., \& Fatimah, S. (2020). KEEFEKTIFAN PENGGUNAAN TEKNIK THINK PAIR SHARE (TPS) DALAM KETERAMPILAN MEMBACA MEMAHAMI BAHASA JERMAN SISWA KELAS X SMA NEGERI 1 KAB. BARRU. Interference: Journal of Language, Literature, and Linguistics, 1(1). 